\title{
Épocas de aplicação de regulador de crescimento e de sombreamento artificial em cultivares de trigo
}

\author{
Application times of growth regulator and of artificial shading in wheat cultivars
}

Lorena Müller Martins, lo_muller@hotmail.com Jeferson Zagonel, jefersonzagonel@uol.com.br Camila Ferreira, cferreira87@hotmail.com

Marina Senger, marina_senger@hotmail.com

Resumo: $\mathrm{O}$ uso do regulador de crescimento trinexapac-ethyl visa reduzir a altura das plantas de trigo evitando assim o acamamento e as perdas ocasionadas por ele. Além disso, o regulador modifica a arquitetura foliar fazendo com que a planta tenha um melhor aproveitamento da radiação solar. Com o objetivo de avaliar os efeitos de épocas de aplicação do regulador de crescimento trinexapac-ethyl, associado ou não ao sombreamento artificial em diferentes estádios de desenvolvimento do trigo, realizaram-se três experimentos na Fazenda Escola da Universidade Estadual de Ponta Grossa, no município de Ponta Grossa, Paraná, dois no ano de 2010 e um no ano de 2011. O delineamento experimental foi de blocos ao acaso com quatro repetições em esquema fatorial, sendo que no ano de 2010 foi 4 x 3 (épocas de aplicação do trinexapac-ethyl x épocas de sombreamento) nas cultivares de trigo Quartzo e Supera, e no ano de 2011 no esquema 4 x 4 (épocas de aplicação do trinexapac-ethyl x épocas de sombreamento), na cultivar Quartzo. Os tratamentos consistiram de quatro épocas de aplicação do trinexapac-ethyl (sem aplicação, no perfilhamento, entre o $1^{\circ} \mathrm{e} \circ 2^{\circ}$ nó perceptível e entre o $2^{\circ}$ e o $3^{\circ}$ nó perceptível) na dose de $100 \mathrm{~g} \cdot \mathrm{ha}^{-1}$ em ambos os anos e de quatro épocas de sombreamento artificial (sem cobertura, da fase de emborrachamento ao espigamento, do espigamento +15 dias (x) e $x+15$ dias) no ano de 2011 de três épocas (sem cobertura, do espigamento + 15 dias ( $\mathrm{x}$ ) e $\mathrm{x}+15$ dias) no ano de 2010. Não houve interação entre os tratamentos para as características avaliadas. Nos dois ensaios realizados não foram observadas diferenças para diâmetro do colmo, área foliar, e índice de colheita. O sombreamento artificial não afetou o número de espigas por metro, de grãos por espigueta e de perfilhos por planta nos dois anos, e o menor peso de grãos ocorreu quando o sombreamento foi realizado no final da antese e enchimento de grãos $(X+15)$. O número de espiguetas por espigas não foi influenciado pelo sombreamento na safra 2010, porém na safra 2011 o sombreamento no final do espigamento + 15 dias aumentou o número de espiguetas por espiga. O trinexapac-ethyl não influenciou a maioria dos componentes de produção avaliados. O sombreamento não interferiu na altura de plantas. Na safra 2011, com a aplicação do regulador de crescimento entre o primeiro e segundo nó e entre o segundo e terceiro nó perceptível a altura de plantas foi menor. A produtividade não foi afetada pelas épocas de aplicação do trinexapac-ethyl. Na safra 2011 o sombreamento artificial efetuado no final da antese e enchimento de grãos $(X+15$ dias) resultou em menor produtividade.

Palavras-chave: Triticum aestivum; trinexapac-ethyl; sombreamento.

Abstract: The use of the growth regulator trinexapac-ethyl intends to reduce the height of wheat plants, avoiding lodging and losses caused by it. In addition, it causes changes on the leaf architecture making the plant have a better use of solar radiation. Intending to evaluate the effects of application times of the growth regulator trinexapac-ethyl with or without artificial shade at different growth stages of wheat, three experiments were made in the Farm School of Ponta Grossa State University, in the municipality of Ponta Grossa, Parana, two in 2010 and one in 2011. The experimental design was made with randomized blocks of four repetitions in a factorial design, where in 2010 it was $4 \times 3$ (times of application of trinexapac-ethyl $x$ shading time) in Quartzo and Supera wheat cultivar and in 2011 it was made in $4 \times 4$ schedule (time of application of trinexapac-ethyl $x$ shading time), in Quartzo cultivar. Treatments consisted in four periods of application of trinexapac-ethyl (without application, in the sequence, between first and second 


\begin{abstract}
perceivable knot and between second and third perceivable knot) with the dose of 100 g. ha $\mathrm{a}^{-1}$ in each years and four seasons of shading (without coverage, in the rubbery to earing stage +15 days $(x), x+15$ days) in 2011 and three seasons (without coverage, the earing stage +15 days $(x)$ and $X+15$ days) in 2010. There was not any interaction observed between the treatments for the evaluated characteristics. There were no differences observed for stem diameter, leaf area and harvest index in both trials. The artificial shade did not affect the number of spikes per meter, grains per spikelet, number of sequences per plant in two years and the lowest grain yield occurred when the shading was done at the end of anthesis and grain filling $(X+15)$. The number of spikelets per spike was not affected by shading in the 2010 harvest, but in the 2011 harvest the period of shading done at the end of earing stage +15 days increased the number of spikelets per spike. The trinexapac-ethyl did not affect most of the yield components evaluated. Shading did not affect the plant height. In the 2011 harvest, with the application of growth regulator between the first and second knot and between the second and third knot visible made the plant height lower. The yield was not affected by trinexapac-ethyl applications timing. In the 2011 harvest the shading done at the end of anthesis and grain filling $(X+15$ days) resulted in lower productivity.
\end{abstract}

Keywords: Triticum aestivum; Trinexapac-ethyl; Shading.

O trigo (Triticum aestivum L.) é um dos cereais mais cultivados e importantes do mundo, representando aproximadamente $30 \%$ da produção mundial de grãos. É uma cultura de grande importância para o Brasil, havendo no país uma demanda crescente por derivados desse cereal (SEAB/ DERAL, 2013). No entanto, a falta de incentivo à produção de trigo, as baixas produtividades e a qualidade inferior, são fatores que estão diretamente relacionados ao deficit anual (CARNEIRO, 2005), sendo o grande desafio, para o Brasil, para sair da condição de importador e alcançar a autossuficiência (SMANHOTTO et al., 2006). A diminuição da produtividade do trigo, entre outros fatores, está muitas vezes relacionada à suscetibilidade ao acamamento de alguns cultivares, o que acarreta também a redução da qualidade dos grãos e o aumento das perdas na operação de colheita (RODRIGUES et al., 2003).

Uma alternativa para contornar esse problema é a aplicação de reguladores de crescimento. Os redutores de crescimento possibilitam o uso de maiores doses de nitrogênio, mesmo em cultivares de porte mais alto, atuando como sinalizadores químicos na regulação do crescimento e no desenvolvimento de plantas, pois podem impedir o alongamento de raízes e caules, a germinação de sementes e o brotamento de gemas, conforme o estádio fenológico de aplicação e a dose utilizada (MATYSIAK, 2006).

Reguladores de crescimento são compostos sintéticos que podem ser utilizados para reduzir o crescimento longitudinal indesejável da parte aérea das plantas sem diminuição da produtividade (RADEMACHER, 2000). O trinexapac-ethyl é um regulador de crescimento utilizado em cereais de inverno, que promove redução acentuada do comprimento do colmo com redução da altura da planta, evitando o acamamento. O trinexapac-ethyl é absorvido pelas folhas, sendo translocado até os nós do colmo, atuando no balanço das giberelinas e afetando a elongação dos entrenós (COSTA et al., 2010).

A aplicação do trinexapac-ethyl muda a arquitetura da folha de trigo, o que provavelmente faz com que a planta tenha um aproveitamento mais eficiente da radiação solar, que pode resultar em aumento de produtividade. O efeito do trinexapac-ethyl pode ser observado em média de 15 a 20 dias após a aplicação, sendo que a inclinação da folha pode variar de acordo com a cultivar e pode explicar os ganhos de produtividade em cultivares de porte baixo, mesmo sem a ocorrência de acamamento (PENCKOWSKI et al., 2010).

A produção de biomassa pelas culturas está relacionada à quantidade de radiação fotossinteticamente ativa interceptada e absorvida pelas folhas, e à eficiência com que estas convertem a energia radiante em energia química, pela fotossíntese, a qual é responsável pelo enchimento de grãos (HEINEMANN et al., 2006). Willey e Holliday (1971) concluíram que períodos de alta nebulosidade ocasionam deficiência fotossintética, resultando em menor peso de grãos na cultura do trigo.

O baixo índice de radiação solar incidente na Região Sul do Brasil pode ser responsável pela menor produtividade da cultura do trigo em relação a outras regiões (ZAGONEL; FERNANDES, 2007). Nesse sentido, o sombreamento artificial associado à aplicação do regulador de crescimento trinexapac-ethyl pode indicar se há relação entre o aumento da produtividade causada pelo uso do regulador, conforme observam vários autores (BERTI et al., 2007; PENCKOWSKI et al., 2009), com a melhor absorção da radiação solar causada pela mudança da arquitetura foliar ocasionada pelo uso do produto. 
Assim, realizaram-se três experimentos, nos anos 2010 e 2011, com o objetivo de avaliar os efeitos de épocas de aplicação do regulador de crescimento trinexapac-ethyl associado ou não ao sombreamento artificial em diferentes estádios de desenvolvimento do trigo.

\section{Material e mÉTOdos}

Foram instalados três experimentos nos anos de 2010 e 2011, na Fazenda Escola "Capão da Onça" da Universidade
Estadual de Ponta Grossa (UEPG), município de Ponta Grossa-PR. O clima de Ponta Grossa é classificado como $\mathrm{Cfb}$, segundo Köppen. O solo das áreas experimentais foi classificado como um Cambissolo Háplico Tb distrófico típico (EMBRAPA, 2006), de textura argilosa. Os resultados das análises químicas encontram-se na Tabela 1. A análise granulométrica do solo forneceu as quantidades de areia $361 \mathrm{~g} \cdot \mathrm{kg}^{-1}$, silte $-179 \mathrm{~g} \cdot \mathrm{kg}^{-1} \mathrm{e}$ argila $-460 \mathrm{~g} \cdot \mathrm{kg}^{-1}$. Dados das características climáticas temperatura e precipitação encontram-se nas Figuras 1 e 2.

Tabela 01: Características químicas do solo. Ponta Grossa, UEPG, 2010/11.

\begin{tabular}{|c|c|c|c|c|c|c|c|c|c|c|}
\hline Profundidade & $\mathrm{pH}$ & $\mathrm{H}+\mathrm{Al}$ & $\mathrm{Ca}$ & $\mathrm{Mg}$ & K & $\mathrm{CTC}^{1}$ & $\mathrm{~V}^{2}$ & $M^{3}$ & $P$ & C \\
\hline $\mathrm{cm}$ & & \multicolumn{4}{|c|}{ cmolc. $\mathrm{dm}^{-3}$} & $(\mathrm{pH} \mathrm{7,0)}$ & \multicolumn{2}{|c|}{$\%$} & $\mathrm{mg} \cdot \mathrm{dm}^{-3}$ & g. $\mathrm{dm}^{-3}$ \\
\hline \multicolumn{11}{|c|}{ ANO 2010} \\
\hline $0-10$ & 5,2 & 6,69 & 5,5 & 1,9 & 0,36 & 14,45 & 53,7 & 0,0 & 19,4 & 36 \\
\hline $10-20$ & 5,0 & 7,20 & 3,9 & 1,5 & 0,29 & 12,89 & 44,1 & 0,0 & 6,8 & 29 \\
\hline \multicolumn{11}{|c|}{ ANO 2011} \\
\hline $0-10$ & 5,6 & 4,96 & 6,4 & 2,0 & 0,53 & 13,89 & 64,3 & 0,0 & 34,4 & 33 \\
\hline $10-20$ & 5,6 & 4,96 & 4,2 & 1,9 & 0,40 & 11,46 & 56,7 & 0,0 & 7,1 & 23 \\
\hline
\end{tabular}

${ }^{1} \mathrm{CTC}=$ Capacidade de troca catiônica do solo a pH 7,0; ${ }^{2} \mathrm{~V}=$ Saturação por bases; ${ }^{3} \mathrm{M}=$ Saturação por alumínio. Métodos de extração: $\mathrm{pH}=\mathrm{CaCl} 2, \mathrm{H}+\mathrm{Al}=$ Solução tampão SMP, $\mathrm{Ca}$ e Mg $=\mathrm{KCl} 1$ mol. L-1, P e K = Mehlich -1 e C - orgânico = Walkley-Black.

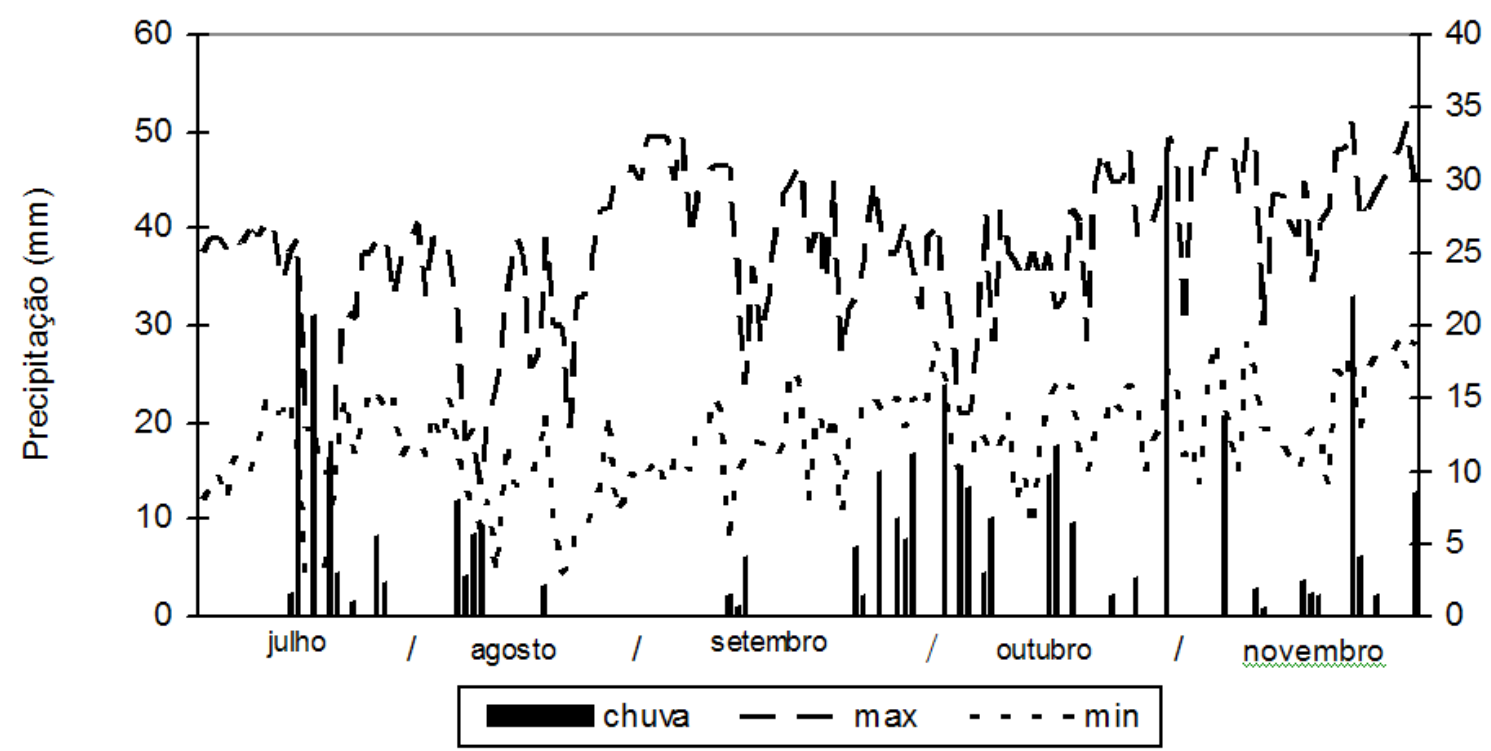

Figura 01: Dados de temperatura e precipitação em Ponta Grossa - PR no decorrer da safra de trigo (2010). 


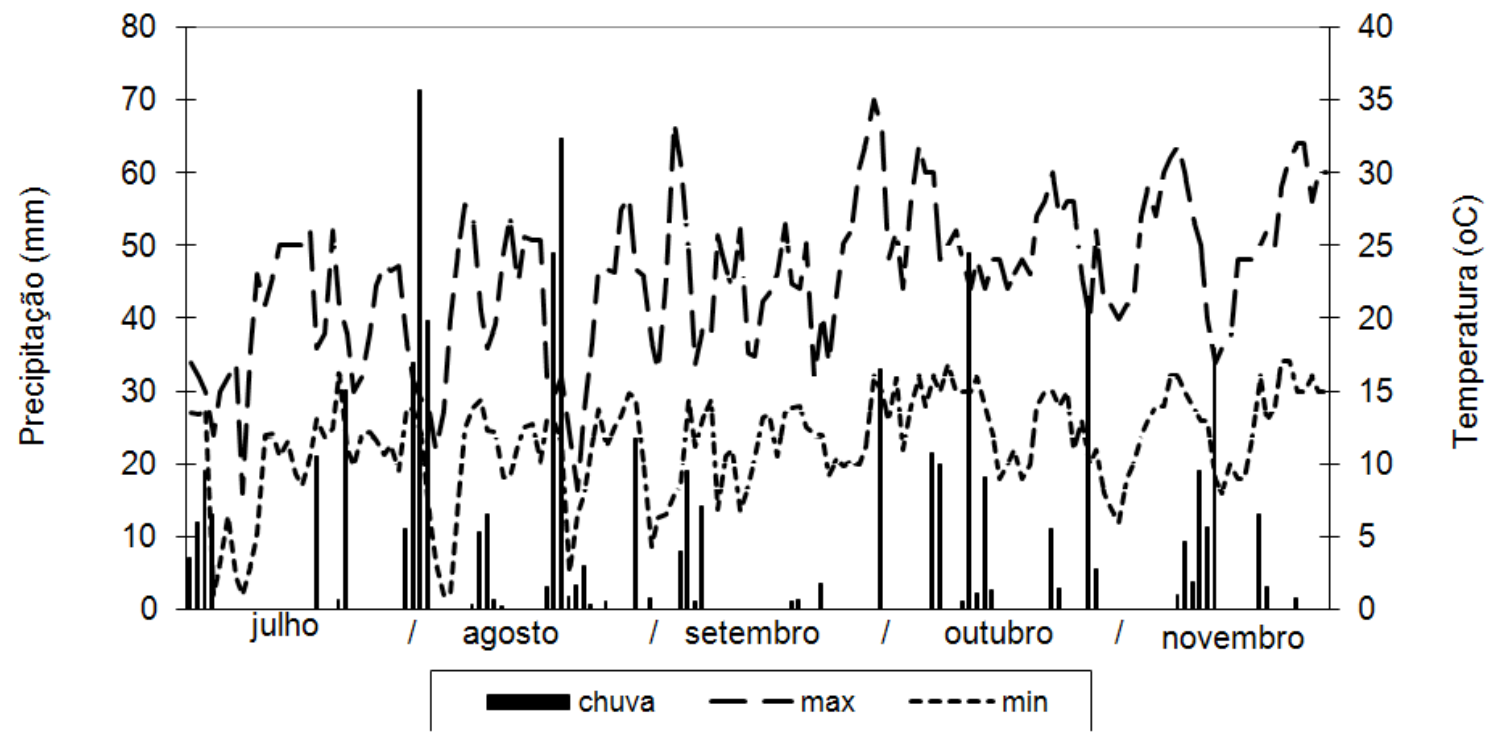

Figura 2: Dados de temperatura e precipitação em Ponta Grossa - PR no decorrer da safra de trigo (2011).

Os experimentos diferiram-se conforme a cultivar semeada nos anos 2010 e 2011. Em 2010 semearam-se as cultivares Quartzo e Supera sob o sistema de "plantio direto na palha", sendo milho a cultura antecessora. A dessecação da área foi realizada com glifosato $+2,4-D(720+670 \mathrm{~g}$ e.a. ha $^{-1}$ ) aos 25 dias antes da semeadura, e, um dia antes da semeadura do trigo, realizou-se uma dessecação com paraquate + diuron $(300+150$ g e.a. ha-1 $)$ para eliminar as plantas daninhas presentes na área.

A adubação de base foi realizada com $300 \mathrm{~kg} \mathrm{ha}^{-1} \mathrm{da}$ fórmula comercial 05-25-25, o que equivale a $15 \mathrm{~kg} \mathrm{ha}^{-1}$ de nitrogênio, $75 \mathrm{~kg} \mathrm{ha}{ }^{-1}$ de $\mathrm{P}_{2} \mathrm{O}_{5}$ e $75 \mathrm{~kg} \mathrm{ha}^{-1}$ de $\mathrm{K}_{2} \mathrm{O}$, sendo aplicados na forma de ureia, superfosfato simples e nitrato de potássio respectivamente. Em cobertura foram utilizados $67,5 \mathrm{~kg} \mathrm{ha}^{-1}$ de $\mathrm{N}$, na forma de ureia, aplicados no início do perfilhamento.

O controle de pragas e doenças no tratamento de sementes consistiu de $35,0 \mathrm{~g}$ de thiamethoxam e da mistura pronta de 50 + $50 \mathrm{~g}$ de carboxim + tiram por $100 \mathrm{~kg}$ de sementes.

O controle de doenças foi realizado com a aplicação de $56,25+24,00$ g.ha-1 de trifloxistrobina + ciproconazol no início da elongação do colmo, aos 43 dias após a emergência das plantas (DAE); e de duas aplicações de $60+120$ g.ha-1 de óleo metilado de soja, uma no final da elongação/ início do espigamento (65 DAE) e outra no final do florescimento (84 DAE). O controle de pragas foi realizado com uma aplicação de 62,0 g.ha-1 de thiamethoxam + lambdacialotrina aos 22 DAE e uma de $160 \mathrm{~g} \mathrm{ha}^{-1}$ de dimetoato aos 43 FAE. Para o controle das plantas daninhas em pós-emergência, utilizou-se 3,0 g.ha-1 de metsulfuron-metílico adicionado de óleo mineral a 0,5\% v. $\mathrm{v}^{-1}$ aos 43 DAE. $O$ volume de calda utilizado em todos os tratamentos foi de 150 L.hä . $^{-1}$

O delineamento experimental utilizado foi de blocos ao acaso em esquema fatorial 4 × 3 (épocas de aplicação do trinexapac-ethyl $x$ épocas de sombreamento) com quatro repetições.

No ano de 2011, a semeadura da cultivar Quartzo também foi realizada em sistema de "plantio direto na palha", sendo milho a cultura antecessora.

A adubação de base foi realizada com $300 \mathrm{~kg} \cdot \mathrm{ha}^{-1} \mathrm{da}$ fórmula comercial 14-34-00, o que equivale a $42 \mathrm{~kg} \cdot \mathrm{ha}^{-1}$ de nitrogênio e $102 \mathrm{~kg}$.ha-1 de $\mathrm{P}_{2} \mathrm{O}_{5}$, aplicados na forma de ureia e superfosfato simples. Em cobertura se utilizou $50 \mathrm{~kg} \cdot \mathrm{ha}^{-1}$ de $\mathrm{N}$ e $50 \mathrm{~kg} \mathrm{ha}{ }^{-1}$ de $\mathrm{K}_{2} \mathrm{O}$ na fórmula comercial 25-00-25, na forma de ureia e nitrato de potássio, aplicados no início do perfilhamento.

Tanto o tratamento de sementes quanto o manejo de controle de plantas daninhas, pragas e doenças foram realizados da mesma forma que no ano anterior.

O delineamento experimental utilizado foi de blocos ao acaso em esquema fatorial 4 x 4 (épocas de aplicação do trinexapac-ethyl $x$ épocas de sombreamento) com quatro repetições.

Nas duas safras as parcelas foram compostas de 16 linhas de $6,0 \mathrm{~m}$ de comprimento espaçadas de 0,17 m, totalizando 16,32 $\mathrm{m}^{2}$. Como área útil foram consideradas as 8 linhas centrais eliminando 1 metro em cada extremidade da parcela $\left(5,44 \mathrm{~m}^{2}\right)$. 
Os tratamentos consistiram de quatro épocas de aplicação do trinexapac-ethyl (sem aplicação, no perfilhamento, entre o $1^{\circ}$ e o $2^{\circ}$ nó perceptível e entre o $2^{\circ}$ e o $3^{\circ}$ nó perceptível) na dose de 100 g.ha-1. No ano de 2010, o sombreamento foi realizado em três épocas (sem cobertura, do espigamento +15 dias ( $\mathrm{x}$ ) e $\mathrm{x}+15$ dias) e no ano de 2011, o sombreamento artificial foi realizado em quatro épocas (sem cobertura, da fase de emborrachamento ao espigamento, do espigamento +15 dias ( $x$ ) e $x+15$ dias).

$\mathrm{O}$ trinexapac-ethyl foi aplicado por meio de pulverizador costal, a pressão constante de $206,85 \mathrm{kPa}$, pelo $\mathrm{CO}_{2}$ comprimido, com barra de 3,0 m de largura munida de seis bicos com pontas jato plano "leque" XR 110-02, distanciados de 0,50 m um do outro e volume de calda de 150 L.ha1. Na aplicação a cultura estava no estádio 22 da escala de Zadoks et al. (1974) no momento da primeira aplicação, estádio 31 na segunda aplicação e 33 na terceira aplicação.

O sombreamento artificial foi simulado pelo uso de sombrite, com redução de $35 \%$ da radiação, colocado a uma altura de 1,30 m do solo com a utilização de estruturas de ferro no formato de " $L$ ", sendo ligada uma a outra por bambu, em que foram amarrados os sombrites com a utilização de abraçadeiras de nylon.

$\mathrm{Na}$ fase da antese foram colhidas as plantas de um metro de linha, e dessas retiradas aleatoriamente 10 plantas de trigo por parcela para as avaliações de área foliar, altura da planta, largura e comprimento da folha bandeira.

A área foliar foi avaliada por meio do aparelho digital integrador óptico de área, o qual possui uma precisão de $0,01 \mathrm{~cm}^{2}$. Para a determinação da área foliar foram somadas as áreas de todas as folhas de dez plantas por parcela. A altura de plantas foi determinada medindo-se o comprimento da planta desde o solo até a base da espiga.

Na planta-mãe foram medidos o comprimento e a largura da folha bandeira. O comprimento foi determinado na parte central da folha, da base até a ponta da folha e a largura no centro da folha, fazendo-se uso de uma régua graduada.

Antes da colheita foram colhidas as plantas de dois metros de linha de cada parcela para determinar o número de espigas por metro. Dessas plantas foram selecionadas aleatoriamente dez, as quais foram utilizadas para determinação do número de grãos por espiga e comprimento do pedúnculo.

Grãos, folhas, colmos e ráquis das plantas utilizadas para determinação dos componentes de produção foram colocados em estufa de ventilação, forçada a uma temperatura de $65^{\circ} \mathrm{C}$ por 48 horas para determinação do Índice de Colheita Aparente (IC). O IC foi calculado por meio da fórmula:

\section{$I C(\%)=\frac{\text { Produçãodegrãos }(g)}{\text { Produçãodefitomass } a(g)} \times 100$}

Nas duas safras se colheu a área útil das parcelas para a determinação da produtividade, sendo corrigida a umidade para 13\%. Dos grãos colhidos foi determinada a massa de mil grãos

Os dados obtidos foram submetidos à análise de variância pelo teste de $F$, e quando significativas as diferenças entre as médias, foram comparadas pelo teste de Tukey a $5 \%$ de probabilidade.

\section{RESULTAdOS E DISCUSSÃO}

Não ocorreram interações significativas entre o sombreamento e o trinexapac-ethyl para as variáveis estudadas.

Nos experimentos realizados no ano 2010, não ocorreram diferenças significativas para o comprimento e largura da folha bandeira com o sombreamento e com a aplicação do regulador de crescimento nas diferentes épocas e em ambas as cultivares (Tabela 2). Esse resultado pode ter ocorrido devido à deficiência hídrica observada na safra 2010, uma vez que o efeito do redutor de crescimento é minimizado nessas condições (MATYSIAK, 2006; RODRIGUES et al., 2003).

Na safra 2011, ano de características climáticas normais para a época da condução do experimento, não houve diferença significativa para as épocas de sombreamento; já a aplicação do trinexapac-ethyl afetou significativamente o comprimento e a largura da folha bandeira, sendo que o comprimento foi menor quando aplicado o regulador de crescimento entre o primeiro e o segundo nó, e a largura diminuiu em todas as épocas de aplicação do regulador de crescimento (Tabela 3). Segundo Fernandes (2009), tanto o comprimento como a largura da folha bandeira são características de cada cultivar, mas que podem ser alteradas de acordo com as condições climáticas ou técnicas de manejo empregadas, como o uso de regulador de crescimento. Ainda, em cereais de inverno, folhas compridas são mais decumbentes, sendo que folhas curtas são mais eretas, estando associadas a uma melhor distribuição no dossel, fazendo com que a interceptação solar seja melhor. 
Tabela 2: Comprimento (CFB) e largura (LFB) da folha bandeira em função de épocas de aplicação de regulador de crescimento e de sombreamento artificial nas cultivares de trigo Supera e Quartzo. Ponta Grossa, PR, 2010.

\begin{tabular}{|c|c|c|c|c|}
\hline \multirow[b]{2}{*}{ SOMBREAMENTO } & \multicolumn{2}{|c|}{ SUPERA } & \multicolumn{2}{|c|}{ QUARTZO } \\
\hline & CFB & LFB & CFB & LFB \\
\hline Sem & $12,89 \mathrm{a}$ & $0,79 \mathrm{a}$ & $11,18 a$ & $0,74 \mathrm{~b}$ \\
\hline Fim espigamento +15 dias $(X)$ & $12,26 \mathrm{a}$ & $0,76 a$ & $11,63 a$ & $0,79 a$ \\
\hline$X+15$ dias & $13,62 \mathrm{a}$ & $0,77 \mathrm{a}$ & $12,48 \mathrm{a}$ & $0,79 a$ \\
\hline \multicolumn{5}{|l|}{ TRINEXAPAC-ETHYL } \\
\hline Sem & $13,20 \mathrm{a}$ & $0,78 \mathrm{a}$ & $11,47 a$ & $0,77 \mathrm{a}$ \\
\hline Perfilhamento & $12,65 \mathrm{a}$ & $0,78 \mathrm{a}$ & $12,39 a$ & $0,77 \mathrm{a}$ \\
\hline $1^{\circ}$ e $2^{\circ}$ nó & $13,25 \mathrm{a}$ & $0,77 \mathrm{a}$ & $11,52 \mathrm{a}$ & $0,76 a$ \\
\hline $2^{\circ}$ e $3^{\circ}$ nó & $12,60 \mathrm{a}$ & $0,75 \mathrm{a}$ & $11,68 \mathrm{a}$ & $0,79 a$ \\
\hline$C V$ & 12,45 & 7,31 & 13,77 & 7,32 \\
\hline
\end{tabular}

Médias seguidas por letras distintas na coluna diferem entre si ao nível de significância Tukey 5\%.

Tabela 3: Comprimento (CFB) e largura (LFB) da folha bandeira em função de épocas de aplicação de regulador de crescimento e de sombreamento artificial na cultivar de trigo Quartzo. Ponta Grossa, PR, 2011.

\begin{tabular}{|c|c|c|}
\multirow{2}{*}{ SOMBREAMENTO } & CFB & LFB \\
\cline { 2 - 3 } Sem & $19,90 \mathrm{a}$ & $1,30 \mathrm{a}$ \\
Emborrachamento/Espigamento & $20,07 \mathrm{a}$ & $1,31 \mathrm{a}$ \\
Fim espigamento + 15 dias (X) & $19,71 \mathrm{a}$ & $1,31 \mathrm{a}$ \\
$\mathrm{X}+15$ dias & $19,91 \mathrm{a}$ & $1,32 \mathrm{a}$ \\
\hline TRINEXAPAC-ETHYL $^{*}$ & & $1,37 \mathrm{a}$ \\
\hline Sem & $21,24 \mathrm{a}$ & $1,29 \mathrm{ab}$ \\
$1^{\circ}$ e $2^{\circ}$ nó & $20,33 \mathrm{a}$ & $1,33 \mathrm{ab}$ \\
$2^{\circ}$ e $3^{\circ}$ nó & $17,49 \mathrm{~b}$ & $1,25 \mathrm{~b}$ \\
CV $^{*}$ & $20,53 \mathrm{a}$ & 7,12 \\
\hline
\end{tabular}

Médias seguidas por letras distintas na coluna diferem entre si ao nível de significância Tukey $5 \%$. 
As épocas de sombreamento artificial não interferiram no comprimento do pedúnculo e na altura das plantas para ambas as cultivares na safra 2010 (Tabela 4). Quanto a épocas de aplicação do trinexapac-ethyl, houve diferença significativa somente para o comprimento do pedúnculo da cultivar Supera, quando o trinexapac-ethyl foi aplicado no perfilhamento, entre o primeiro e segundo nó e entre o segundo e terceiro nó perceptível em relação à não aplicação (Tabela 4).

Aplicações tardias reduzem sensivelmente o tamanho das plantas, pois o efeito ocorre sobre os entrenós superiores, mais longos, como o pedúnculo, e podem retardar o espigamento (RODRIGUES et al., 2003). Assim, aplicações após o terceiro nó podem resultar em encurtamento acentuado do pedúnculo, fazendo com que a espiga fique retida na bainha da folha bandeira, o que resultará em problemas na antese e, consequentemente, na produtividade do trigo (PENCKOWSKI et al., 2009).

A ausência de resposta da altura das plantas para a aplicação do trinexapac-ethyl, em ambas as cultivares no ano de 2010, pode ser em razão da baixa precipitação pluvial no decorrer do experimento, um fator importante para a atuação do redutor de crescimento que tem sua ação minimizada em anos de poucas chuvas (RODRIGUES et al., 2003).

Na safra 2011, o sombreamento artificial em todas as épocas não afetou o comprimento do pedúnculo nem a altura das plantas (Tabela 5). No entanto, observou-se que o trinexapac-ethyl promoveu redução da altura de plantas e comprimento do pedúnculo em todas as épocas de aplicação, mais acentuadas quando o produto foi aplicado entre o primeiro e o segundo e entre o segundo e o terceiro nó perceptível (Tabela 5).

Segundo Zagonel e Fernandes (2007), o moento recomendado de aplicação do trinexapac-ethyl é entre o primeiro e o segundo nó perceptível. Berti et al. (2007) comentam que aplicações mais tardias do trinexapac-ethyl deveriam promover uma maior redução da altura das plantas em relação à aplicação mais precoce, visto que a aplicação tardia afeta o comprimento dos entrenós que se formam mais tarde, que são os mais longos, como ocorreu neste trabalho no experimento realizado em 2011.

Tabela 4: Comprimento do pedúnculo (CP) e altura (ALT) de plantas em função de épocas de aplicação de regulador de crescimento e de sombreamento artificial nas cultivares de trigo Supera e Quartzo. Ponta Grossa, PR, 2010.

\begin{tabular}{|c|c|c|c|c|}
\hline \multirow{3}{*}{ SOMBREAMENTO } & \multicolumn{2}{|c|}{ SUPERA } & \multicolumn{2}{|c|}{ QUARTZO } \\
\hline & $\mathrm{CP}$ & ALT & $\mathrm{CP}$ & ALT \\
\hline & \multicolumn{4}{|c|}{-----------------------'cm----------------------- } \\
\hline Sem & $27,5 \mathrm{a}$ & $60,7 a$ & $29,1 \mathrm{a}$ & $65,3 a$ \\
\hline Fim espigamento + 15 dias (X) & $27,3 \mathrm{a}$ & $60,3 \mathrm{a}$ & $28,2 \mathrm{a}$ & $65,2 \mathrm{a}$ \\
\hline$X+15$ dias & $28,2 \mathrm{a}$ & $62,4 \mathrm{a}$ & $28,7 \mathrm{a}$ & $65,6 \mathrm{a}$ \\
\hline \multicolumn{5}{|l|}{ TRINEXAPAC-ETHYL } \\
\hline Sem & $29,2 \mathrm{a}$ & $63,3 a$ & $28,5 \mathrm{a}$ & $65,0 \mathrm{a}$ \\
\hline Perfilhamento & $27,0 \mathrm{~b}$ & $60,3 \mathrm{a}$ & 29,5 a & $66,3 \mathrm{a}$ \\
\hline $1^{\circ}$ e $2^{\circ}$ nó & $27,3 \mathrm{~b}$ & $60,0 \mathrm{a}$ & $28,4 \mathrm{a}$ & $64,9 \mathrm{a}$ \\
\hline $2^{\circ}$ e $3^{\circ}$ nó & $27,1 \mathrm{~b}$ & $60,3 \mathrm{a}$ & $28,2 \mathrm{a}$ & $65,3 \mathrm{a}$ \\
\hline $\mathrm{CV}$ & 4,62 & 5,72 & 5,63 & 3,67 \\
\hline
\end{tabular}

Médias seguidas por letras distintas na coluna diferem entre si ao nível de significância Tukey $5 \%$. 
Tabela 5: Comprimento do pedúnculo (CP) e altura (ALT) das plantas em função de épocas de aplicação de regulador de crescimento e de sombreamento artificial na cultivar de trigo Quartzo. Ponta Grossa, PR, 2011.

\begin{tabular}{|c|cc|}
\hline \multirow{2}{*}{ SOMBREAMENTO } & CP & ALT \\
\cline { 2 - 3 } Sem & $33,4 \mathrm{a}$ & $65,1 \mathrm{a}$ \\
Emborrachamento/Espigamento & $33,6 \mathrm{a}$ & $64,1 \mathrm{a}$ \\
Fim espigamento + 15 dias & $34,9 \mathrm{a}$ & $62,8 \mathrm{a}$ \\
$\mathrm{X}+15$ dias & $34,3 \mathrm{a}$ & $63,7 \mathrm{a}$ \\
\hline TRINEXAPAC-ETHYL & & $73,3 \mathrm{a}$ \\
\hline Sem & $37,6 \mathrm{a}$ & $69,1 \mathrm{~b}$ \\
Perfilhamento & $35,4 \mathrm{~b}$ & $54,8 \mathrm{c}$ \\
1 e 2 nó & $30,9 \mathrm{c}$ & $58,6 \mathrm{c}$ \\
2 e 3 nó & $31,7 \mathrm{c}$ & 6,54 \\
\hline CV & 4,64 & $\mathrm{~cm}-{ }^{2}$ \\
\hline
\end{tabular}

Médias seguidas por letras distintas na coluna diferem entre si ao nível de significância Tukey 5\%.

Na safra 2010, a aplicação do trinexapac-ethyl interferiu significativamente apenas no número de espigas por metro na cultivar Supera (Tabela 6). No entanto, na safra 2011, para a cultivar Quartzo (Tabela 7), a aplicação do trinexapac-ethyl não influenciou apenas a massa de mil grãos; assim, os demais componentes de produção foram influenciados pela época de aplicação do regulador de crescimento. 0 maior número de espigas por metro foi observado quando o trinexapac-ethyl foi aplicado entre o segundo e terceiro nó, seguido da época de aplicação entre o primeiro e segundo nó. Quando não foi aplicado o regulador de crescimento, foi observado um menor número de espigas por metro. O número de grãos por espigueta foi menor quando da não aplicação do produto.

Zagonel e Fernandes (2007) não observaram efeito do trinexapac-ethyl sobre o número de espigas por metro e de espiguetas por espigas em três cultivares de trigo. Porém, Zagonel et al. (2002) verificaram que a aplicação de trinexapac-ethyl promoveu efeito positivo no número de espigas por metro, número de espiguetas por espiga e massa de mil grãos. Esses autores atribuem essa variabilidade dos resultados dos componentes da produção em relação à aplicação do trinexapac-ethyl ao conjunto das variações edafoclimáticas de cada local e à cultivar utilizada.

Tabela 6: Número de espigas por metro (EP), número de grãos por espigueta (GR) e massa de mil grãos (MM) em função de épocas de aplicação de regulador de crescimento e de sombreamento artificial nas cultivares de trigo Supera e Quartzo. Ponta Grossa, PR, 2010.

\begin{tabular}{|c|c|c|c|c|c|c|}
\multirow{2}{*}{ SOMBREAMENTO } & \multicolumn{3}{|c}{ SUPERA } & \multicolumn{3}{c|}{ QUARTZO } \\
\cline { 2 - 8 } & EP & GR & MM (g) & EP & GR & MM (g) \\
\hline Sem & $65,31 \mathrm{a}$ & $1,88 \mathrm{a}$ & $28,03 \mathrm{~b}$ & $55,93 \mathrm{a}$ & $1,52 \mathrm{a}$ & $33,00 \mathrm{a}$ \\
Fim espigamento + 15 dias (X) & $61,05 \mathrm{a}$ & $1,78 \mathrm{a}$ & $29,90 \mathrm{a}$ & $54,15 \mathrm{a}$ & $1,33 \mathrm{a}$ & $33,30 \mathrm{a}$ \\
X+15 dias & $60,35 \mathrm{a}$ & $1,86 \mathrm{a}$ & $26,37 \mathrm{c}$ & $55,26 \mathrm{a}$ & $1,43 \mathrm{a}$ & $30,82 \mathrm{~b}$ \\
\hline TRINEXAPAC-ETHYL & & & & & & $32,78 \mathrm{a}$ \\
\hline Sem & $64,19 \mathrm{ab}$ & $1,83 \mathrm{a}$ & $27,72 \mathrm{a}$ & $53,51 \mathrm{a}$ & $1,40 \mathrm{a}$ & $32,64 \mathrm{a}$ \\
Perfilhamento & $57,07 \mathrm{~b}$ & $1,88 \mathrm{a}$ & $29,01 \mathrm{a}$ & $56,33 \mathrm{a}$ & $1,42 \mathrm{a}$ & $32,53 \mathrm{a}$ \\
1 e 2 nó & $68,08 \mathrm{a}$ & $1,82 \mathrm{a}$ & $27,30 \mathrm{a}$ & $55,89 \mathrm{a}$ & $1,39 \mathrm{a}$ & $31,54 \mathrm{a}$ \\
2 e 3 nó & $59,60 \mathrm{ab}$ & $1,82 \mathrm{a}$ & $28,36 \mathrm{a}$ & $54,73 \mathrm{a}$ & $1,50 \mathrm{a}$ & 3,08 \\
\hline
\end{tabular}

Médias seguidas por letras distintas na coluna diferem entre si ao nível de significância Tukey $5 \%$. 
Com os resultados obtidos para as épocas de sombreamento artificial, verificou-se que apenas a massa de mil grãos foi influenciada pelo tratamento em ambas as cultivares na safra 2010 (Tabela 6). A época de sombreamento que corresponde ao final da antese e enchimento de grãos $(X+$ 15 dias) foi a que mais influenciou na redução do peso de grãos, tanto na cultivar Supera como na Quartzo. Na safra 2011 (Tabela 7), a massa de mil grãos também foi influenciada pelas épocas de sombreamento, sendo que assim como na safra 2010, a época que mais afetou corresponde ao final da antese e enchimento de grãos ( $X+15$ dias).

De acordo com Gent (1994), isso pode ser devido a condições de estresse, em que os assimilados armazenados, antes do início do enchimento dos grãos, podem contribuir com mais de $50 \%$ da sua massa final. Assim, a maior disponibilidade de assimilados próxima à antese pode resultar em mais flores férteis e, consequentemente, em maior número e tamanho de grãos, com mais capacidade de formar grãos cheios (RODRIGUES et. al., 2003). Em trabalho realizado por Willey e Holliday (1971), foi verificado que períodos de alta nebulosidade ocasionam deficiência fotossintética, resultando em menor peso de grãos na cultura do trigo. Plantas submetidas à deficiência luminosa após o florescimento reduziram em $20 \%$ o peso de grãos (JUDEL; MENGEL, 1982). Vários autores verificaram que a baixa luminosidade reduz o número de perfilhos por planta de trigo (FRIEND, 1965b; RICKMAN et al., 1985), fato não observado neste trabalho.

Tabela 7: Número de espigas por metro (EP), número de grãos por espigueta (GR) e massa de mil grãos (MM) em função de épocas de aplicação de regulador de crescimento e de sombreamento artificial na cultivar de trigo Quartzo. Ponta Grossa, PR, 2011.

\begin{tabular}{|c|c|c|c|}
\hline \multirow{2}{*}{ SOMBREAMENTO } & EP & GR & MM \\
\cline { 2 - 4 } & & & -- --- \\
\hline Emborrachamento/Espigamento & $67,37 \mathrm{a}$ & $2,33 \mathrm{a}$ & $46,66 \mathrm{a}$ \\
Fim espigamento + 15 dias (X) & $66,43 \mathrm{a}$ & $2,27 \mathrm{a}$ & $46,73 \mathrm{a}$ \\
X + 15 dias & $66,12 \mathrm{a}$ & $2,33 \mathrm{a}$ & $43,52 \mathrm{~b}$ \\
\hline TRINEXAPAC-ETHYL & & & \\
\hline Sem & $61,81 \mathrm{c}$ & $2,10 \mathrm{~b}$ & $46,85 \mathrm{a}$ \\
Perfilhamento & $64,93 \mathrm{bc}$ & $2,36 \mathrm{a}$ & $46,03 \mathrm{a}$ \\
1 e 2 nó & $67,87 \mathrm{~b}$ & $2,37 \mathrm{a}$ & $44,85 \mathrm{a}$ \\
2 e 3 nó & $74,37 \mathrm{a}$ & $2,28 \mathrm{ab}$ & $44,99 \mathrm{a}$ \\
CV & 8,47 & 5,47 & 5,48 \\
\hline
\end{tabular}

Médias seguidas por letras distintas na coluna diferem entre si ao nível de significância Tukey 5\%.

Não foi observada diferença significativa na área foliar e no índice de colheita, tanto para as épocas de sombreamento artificial como para as épocas de aplicação do trinexapac-ethyl para todas as cultivares nos dois anos de pesquisa (Tabelas 8 e 9). Resultados similares foram observados por Fernandes (2009) nas cultivares Safira, OR-1 e BRS 208, nas quais a aplicação de trinexapac-ethyl não influenciou a área foliar.

Fernandes (2009) comenta que a aplicação do trinexapac-ethyl influencia de forma indireta a área foliar de plantas de trigo, pelos efeitos no número, comprimento e largura das folhas, sendo que esse efeito ocorre em intensidades diferentes conforme a cultivar.

Em trabalho realizado por Berti et al. (2007), foi verificado que o aumento da dose de trinexapac-ethyl elevou o índice de colheita das cultivares Supera e CD-104, mas o mesmo não foi observado nas cultivares Vanguarda e CEP-24. Assim, tais resultados indicam que na resposta do índice de colheita a aplicação do trinexapac-ethyl é variável conforme a cultivar. 
Tabela 8: Área foliar (AF) e índice de colheita (IC) em função de épocas de aplicação de regulador de crescimento e de sombreamento artificial nas cultivares de trigo Supera e Quartzo. Ponta Grossa, PR, 2010.

\begin{tabular}{|c|c|c|c|c|}
\hline \multirow{3}{*}{ SOMBREAMENTO } & \multicolumn{2}{|c|}{ SUPERA } & \multicolumn{2}{|c|}{ QUARTZO } \\
\hline & $\mathrm{AF}$ & IC & AF & IC \\
\hline & $\mathrm{cm}^{-2}$ & & $\mathrm{~cm}^{-2}$ & \\
\hline Sem & $26,72 \mathrm{a}$ & $0,50 \mathrm{a}$ & $20,23 \mathrm{a}$ & $0,50 \mathrm{a}$ \\
\hline Fim espigamento + 15 dias $(X)$ & $29,42 \mathrm{a}$ & $0,52 \mathrm{a}$ & $19,64 \mathrm{a}$ & $0,48 \mathrm{a}$ \\
\hline$X+15$ dias & 30,35 a & $0,50 \mathrm{a}$ & $20,60 \mathrm{a}$ & $0,48 \mathrm{a}$ \\
\hline \multicolumn{5}{|l|}{ TRINEXAPAC-ETHYL } \\
\hline Sem & 31,81 a & $0,49 a$ & $19,19 a$ & $0,50 \mathrm{a}$ \\
\hline Perfilhamento & $28,36 \mathrm{a}$ & $0,50 \mathrm{a}$ & $21,99 a$ & $0,50 \mathrm{a}$ \\
\hline 1 e 2 nó & $27,61 \mathrm{a}$ & $0,52 \mathrm{a}$ & 17,99 a & $0,47 a$ \\
\hline 2 e 3 nó & $27,53 \mathrm{a}$ & $0,50 \mathrm{a}$ & $21,48 a$ & $0,49 a$ \\
\hline CV & 23,85 & 16,47 & 24,34 & 10,41 \\
\hline
\end{tabular}

Médias seguidas por letras distintas na coluna diferem entre si ao nível de significância Tukey $5 \%$.

Tabela 9: Área foliar (AF) e índice de colheita (IC) em função de épocas de aplicação de regulador de crescimento e de sombreamento artificial na cultivar de trigo Quartzo. Ponta Grossa, PR, 2011.

\begin{tabular}{|c|cc|}
\multirow{2}{*}{ SOMBREAMENTO } & AF & IC \\
\cline { 2 - 3 } Sem & $16,15 \mathrm{a}$ & $0,50 \mathrm{a}$ \\
Emborrachamento/Espigamento & $16,57 \mathrm{a}$ & $0,52 \mathrm{a}$ \\
Fim espigamento + 15 dias (X) & $16,79 \mathrm{a}$ & $0,50 \mathrm{a}$ \\
X + 15 dias & $17,46 \mathrm{a}$ & $0,44 \mathrm{a}$ \\
\hline TRINEXAPAC-ETHYL & & $0,52 \mathrm{a}$ \\
\hline Sem & $17,37 \mathrm{a}$ & $0,50 \mathrm{a}$ \\
\hline Perfilhamento & $16,52 \mathrm{a}$ & $0,45 \mathrm{a}$ \\
1 e 2 nó & $18,23 \mathrm{a}$ & $0,50 \mathrm{a}$ \\
2 e 3 nó & $17,85 \mathrm{a}$ & 18,61 \\
\hline CV & 36,96 & $\mathrm{c}$ - \\
\hline
\end{tabular}

Médias seguidas por letras distintas na coluna diferem entre si ao nível de significância Tukey $5 \%$.

Não foram observadas diferenças de produtividade para as épocas de sombreamento artificial e também para as épocas de aplicação do trinexapc-ethyl nas cultivares Quartzo e Supera safra 2010 (Tabela 10). Na safra 2011, não ocorreram diferenças significativas para as épocas de aplicação do regulador de crescimento, mas, para as épocas de sombreamento, observou-se que houve redução de produtividade quando o sombreamento artificial foi realizado na época correspondente ao final da antese e enchimento de grãos ( $X+15$ dias) em relação a não simulação de sombreamento (Tabela 11).
Matysiak (2006) relata que em anos de alta precipitação o uso do trinexapac-ethyl promove aumento da produtividade, resultado não observado em anos de deficit hídrico. Essa resposta não foi observada neste trabalho, tanto na safra 2010, quando ocorreu deficit hídrico, como na safra 2011, que foi um ano com elevada precipitação pluvial.

Lima e Lovato (1995) comentam que a falta de resposta da produtividade e de seus componentes à aplicação de reguladores de crescimento pode estar relacionada à ausência de acamamento, propiciada pelas condições climáticas e de fertilidade do solo. Já Zagonel e Fernandes (2007) 
observaram que, independentemente da ocorrência do acamamento, o trinexapac-ethyl promove aumento da produtividade na cultura do trigo, decorrente da melhor distribuição de fotoassimilados para os grãos, já que a altura e a massa das plantas diminuem. Lozano e Leaden (2001) atribuem o aumento de produção causado pelo trinexapac-ethyl às mudanças na arquitetura foliar das plantas, especialmente da angulação da folha-bandeira, que fica mais ereta.
A menor produtividade obtida pela cultivar Quartzo (Tabela 11), para o sombreamento na fase de antese ao início de enchimento de grãos ( $X+15$ dias), pode estar relacionada à menor massa de grãos (Tabela 7), pois a redução da radiação solar no início do enchimento de grãos $(X+15$ dias) tem maiores efeitos na massa de grãos, visto que nessa fase o número de grãos já está definido.

Tabela 10: Produtividade em função de épocas de aplicação de regulador de crescimento e de sombreamento artificial na cultivar de trigo Supera. Ponta Grossa, PR, 2010.

\begin{tabular}{|c|c|c|}
\hline \multirow{2}{*}{ SOMBREAMENTO } & SUPERA & QUARTZO \\
\cline { 2 - 3 } Sem & ------------ kg.ha-1------------ \\
\hline Fim espigamento + 15 dias (X) & $1825 \mathrm{a}$ & $2563 \mathrm{a}$ \\
$\mathrm{X}+15$ dias & $1861 \mathrm{a}$ & $2286 \mathrm{a}$ \\
\hline TRINEXAPAC-ETHYL & $1656 \mathrm{a}$ & $2270 \mathrm{a}$ \\
\hline Sem & & $2294 \mathrm{a}$ \\
Perfilhamento & $1825 \mathrm{a}$ & $2497 \mathrm{a}$ \\
1 e 2 nó & $1766 \mathrm{a}$ & $2247 \mathrm{a}$ \\
2 e 3 nó & $1641 \mathrm{a}$ & $2456 \mathrm{a}$ \\
CV & $1972 \mathrm{a}$ & 23,99 \\
\hline
\end{tabular}

Médias seguidas por letras distintas na coluna diferem entre si ao nível de significância Tukey $5 \%$.

Tabela 11: Produtividade em função de épocas de aplicação de regulador de crescimento e de sombreamento artificial na cultivar de trigo Quartzo. Ponta Grossa, PR, 2011.

\begin{tabular}{|c|c|}
\hline SOMBREAMENTO & QUARTZO \\
\cline { 2 - 2 } Sem & kg.ha $^{-1}$ \\
\hline Emborrachamento/Espigamento & $3032 \mathrm{a}$ \\
Fim espigamento +15 dias $(\mathrm{X})$ & $2974 \mathrm{ab}$ \\
X +15 dias & $2815 \mathrm{ab}$ \\
\hline TRINEXAPAC-ETHYL & $2718 \mathrm{~b}$ \\
\hline Sem & $2779 \mathrm{a}$ \\
\hline Perfilhamento & $2933 \mathrm{a}$ \\
1 e 2 nó & $2966 \mathrm{a}$ \\
2 e 3 nó & $2859 \mathrm{a}$ \\
CV & 9,53 \\
\hline
\end{tabular}

Médias seguidas por letras distintas na coluna diferem entre si ao nível de significância Tukey 5\%. 


\section{CONCLUSÃO}

1. Na safra 2010, apenas o pedúnculo foi reduzido com as aplicações do regulador de crescimento na cultivar Supera.

2. Na safra 2011, com a aplicação do regulador de crescimento, houve redução do comprimento do pedúnculo e da altura das plantas de trigo em todos os tratamentos, comparando-se com a testemunha.

3. Em ambas as safras, com o sombreamento artificial na fase correspondente ao final da antese e início do enchimento de grãos $(X+15)$, houve redução na massa de grãos nas duas cultivares.

4. O sombreamento artificial, na fase correspondente ao final da antese e início do enchimento de grãos (X +15 dias), reduziu a produtividade da cultivar Quartzo na safra 2011, mas na safra de 2010 não houve essa redução.

5. O trinexapac-ethyl não interferiu na produtividade em ambas as safras, tanto na cultivar Quartzo como na cultivar Supera, independentemente da época em que foi aplicado.

\section{REFERÊNCIAS}

BERTI, M.; ZAGONEL, J.; FERNANDES, E.C. Produtividade de cultivares de trigo em função do trinexapac-ethyl e doses de nitrogênio. Scientia Agrária, v. 8, n. 2, p.127134, 2007

CARNEIRO, L. M. T. A. et al. Diferentes épocas de colheita, secagem e armazenamento na qualidade de grãos de trigo comum e duro. Bragantia, v.64, n.1, p.127-137, 2005

COSTA, N. V. et al. Efeito do trinexapac-ethyl na anatomia foliar de quatro espécies de grama. Planta Daninha, v. 28, n. 3 , p. 551-560, 2010

EMBRAPA - Empresa Brasileira de Pesquisa Agropecuária Sistema brasileiro de classificação de solos. 2. ed. Brasília: Embrapa, 2006

FERNANDES, E.C. População de plantas e regulador de crescimento afetando a produtividade de cultivares de trigo. Ponta Grossa: 2009. 119 f. Dissertação (Mestrado em Agronomia) - Universidade Estadual de Ponta Grossa, Ponta Grossa, 2009.
FRIEND, D.J.C. Tillering and leaf production in wheat as affected by temperature and light intesity. Canadian Journal of Botany, v.43, p.1063-1076, 1965b.

GENT, M. P. N. Photosynthate reserves during grain filling in winter wheat. Agronomy Journal, Madison, v.86, p.159-167, 1994

HEINEMANN, A. B. Eficiência de uso da radiação solar na produtividade do trigo decorrente da adubação nitrogenada. Revista Brasileira de Engenharia Agrícola e Ambiental, v.10, n.2, p.352-356, 2006.

JUDEL, G.K.; MENGEL, K. Effect of shading on nonstructural carbohydrates and their turnover in culms on leaves during the grain filling period of spring wheat. Crop Science, v.22, p.958-962, 1982.

LOZANO, C. M.; LEADEN, M. I. Novedades sobre el uso de reguladores de crecimiento en trigo. Jornadas de actualización profesional: Trigo 2001, p. 34-35, 2001.

LIMA, M.R.S.; LOVATO, C. Efeito do cloreto de Chlormequat sobre quatro cultivares de trigo em duas épocas de semeadura. Revista Científica do Centro de Ciências Rurais, v. 25, p. 371-374, 1995.

MATYSIAK, K. Influence of trinexapac-ethyl on growth and development of winter wheat. Journal of Plant Protection Research, v. 46, n. 2, p. 133-143, 2006.

PENCKOWSKI, L. P.; ZAGONEL, Z; FERNANDES, E. C. Nitrogênio e redutor de crescimento em trigo de alta produtividade. Acta Scientiarum Agronomy, v. 31, n. 3, p. 473-479, 2009

PENCKOWSKI, L.H.; ZAGONEL, J.; FERNANDES E.C. Qualidade industrial do trigo em função do trinexapac-ethyl e doses de nitrogênio. Ciência e agrotecnologia, v.34, p.1492-1499, 2010.

RADEMACHER, W. Growth retardants: Effects on gibberellin bioproduction synthesis and other metabolic pathways. Annual Review of Plant Physiology and Plant Molecular Biology, v. 51, p. 501-531. 2000

RICKMAN, R.W.; KLEPPER, B.; PETERSON, C.M. Wheat seedling growth and developmental response to incident photosynthetically active radiation. Agronomy Journal, v.77, p.283-287, 1985

RODRIGUES, O.; DIDONETE, A.D.; TEIXEIRA, C.C.M.; ROMAN, S. E. Redutores de crescimento. Passo Fundo: EMBRAPA, 2003. (Circular Técnica $n^{\circ} 14$ ). 
SMANHOTTO, A. et al. Características físicas e fisiológicas na qualidade industrial de cultivares e linhagens de trigo e triticale. Revista Brasileira Engenharia Agrícola Ambiental, v.10, n.4, p.867-872, 2006.

\section{SECRETARIA DE ESTADO DA AGRICULTURA E DO} ABASTECIMENTO / DEPARTAMENTO DE ECONOMIA RURAL - SEAB/DERAL. Trigo - Análise da Conjuntura Agropecuária, fevereiro de 2013. Disponível em: $<$ http://www.agricultura.pr.gov.br/arquivos/File/deral/ Prognosticos/Trigo_2013.pdf>.

WILLEY, R.W.; HOLLIDAY, R. Plant population and shading studies in barley. Journal of Agricultural Science, v.77, p.445-452, 1971.

ZADOKS, J. C. et al. A decimal code for the growth stages of cereals. Weed Research, v. 14, n. 6, p. 415-421, 1974.

ZAGONEL, J.; VENANCIO, W.S.; KUNZ, R.P. Efeito de regulador de crescimento na cultura do trigo submetido a diferentes doses de nitrogênio e densidade de plantas. Planta Daninha, v.20, n.3, p.471-476, 2002.

ZAGONEL, J.; FERNANDES, E.C. Doses e épocas de aplicação de redutor de crescimento afetando cultivares de trigo em duas doses de nitrogênio. Planta Daninha, v.25, n.2, p. 331-339, 2007. 